\title{
Ultrasonographic Evaluation of Changes in Thyroid Volume In Women During Pregnancy and Lactation
}

\section{Mete Özdikici*}

Department of Radiology, Bakırköy Training and Research Hospital, Turkey

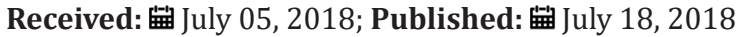

*Corresponding author: Mete Özdikici, Department of Radiology, Bakırköy Training and Research Hospital, İstanbul, Turkey

\section{Abstract}

Objectives: Thyroid gland volume may vary physiologically during pregnancy and lactation. We aimed to determine ultrasonographic changes in thyroid volume in this study.

Materials and Methods: The thyroid ultrasound in 30 mothers was performed at the 9th months of gestation, and also 6th and 12th months after delivery, to calculate thyroid volume.The volume of each lobe was estimated in cubic centimeters using the equation of Brunn et al. The volume of each thyroid gland was obtained by collecting the volume of the right and left lobes. The data were analyzed using SPSS, version 15.0 package program.

Results: The mean volume of the thyroid gland in women in the control group was $11.95 \pm 1.90 \mathrm{~mL}$. When compared with the control group, a significant increase in thyroid gland volume was seen in the third trimester. Decrease at the sixth month after delivery was not significant. But the decline in the values in the twelfth month was statistically significant.

Conclusion: Knowing the limits of this physiological increase will be important in distinguishing it from other possible pathologies. We think that the mean thyroid volume values we find will be useful in daily clinical practice.

Keywords: Thyroid Volume; Pregnancy; Lactation; Ultrasonography

\section{Introduction}

Goiter simply refers to the thyroid gland that grows due to iodine deficiency [1,2]. Thyroid gland volume may vary physiologically during pregnancy and lactation in healthy women. After delivery, there is a decrease in volume until the twelfth month [3]. It is important to determine the volume and structure of gland in the diagnosis and treatment of thyroid diseases by ultrasonography, which is a cheap, harmless and widely used method $[3,4]$. We aimed to determine ultrasonographic changes in thyroid volume during pregnancy and lactation in our study and to compare with literature data.

\section{Materials and Methods}

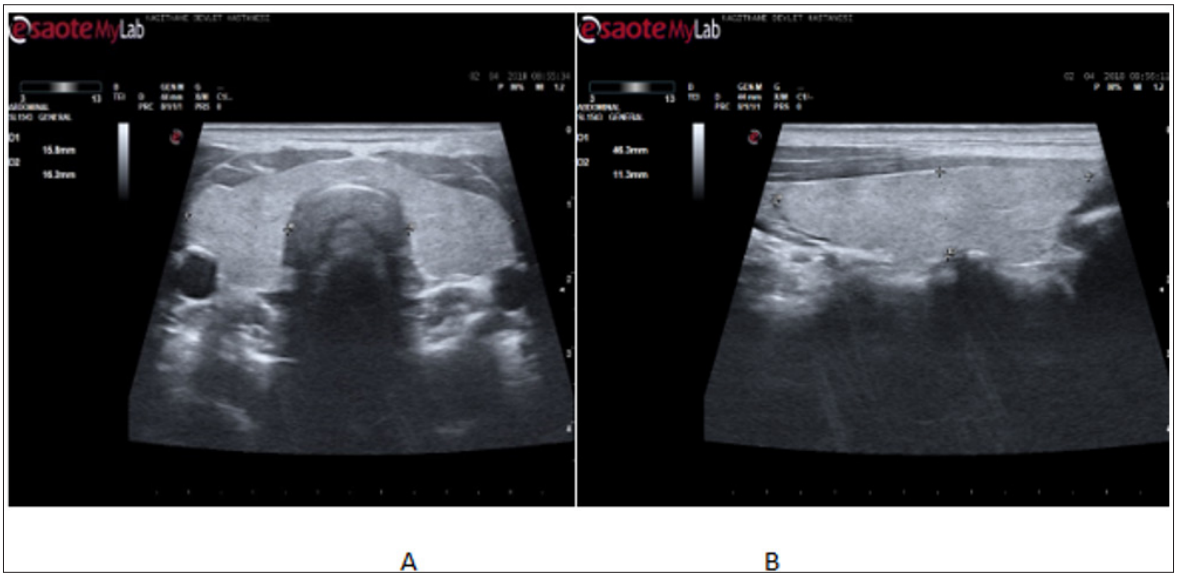

Figure 1: Ultrasound image (and line diagram) of the thyroid gland on transverse (a) and longitudinal (b) scans showing the measurement planes. 
Our study was carried out retrospectively with ultrasonographic archive scanning. The thyroid ultrasound in 30 mothers was performed at the $9^{\text {th }}$ months of gestation, and also $6^{\text {th }}$ and $12^{\text {th }}$ months after delivery, to calculate thyroid volume. The results were compared with the control group of women who had not delivered in the last year. The subjects who detected thyroid lesion on ultrasonography were not included in the study.During the ultrasonographic examination, the subjects rested in a supine position with their necks slightly extended. The mediolateral dimension of both lobes was measured on the transverse image (Figure 1a). The craniocaudal and the anteroposterior dimensions were measured on the longitudinal image (Figure $1 \mathrm{~b}$ ). The volume of each lobe was estimated in cubic centimeters using the equation of Brunn et al. [5].

Volume of lobe $(\mathrm{cm} 3)=$ mediolateral $(\mathrm{ML})$ dimension $(\mathrm{cm}) \times$ craniocaudal $(C C)$ dimension $(\mathrm{cm}) \times$ anteroposterior $(A P)$ dimension $(\mathrm{cm}) \times 0.479$ [conversion factor $]$.

The volume of each thyroid gland was obtained by collecting the volume of the right and left lobes. Isthmus volume was not

included in this calculation.Thyroid volumes were represented by the value of mean \pm standard deviation in Table 1 . The data were analyzed using SPSS, version 15.0 package program.

\section{Results}

We took care not to have thyroid diseases in the women we included in our study. No changes in the echogenicity or echo structure of thyroid gland were noted. The measurements we made are shown in (Table 1).The mean volume of the thyroid gland in women in the control group was $11.95 \pm 1.90 \mathrm{~mL}$. The mean gland volume in pregnant women in the third trimester was $17.20 \pm$ $1.2 \mathrm{~mL}$. This increase was statistically significant $(\mathrm{P}<0.01)$.In the sixth months postpartum, the mean gland volume with ultrasound was found to be $15.90 \pm 1.0 \mathrm{~mL}$. This decrease of $8 \%$ was not statistically significant $(\mathrm{P}>0.05)$. In the twelfth months after the delivery, the mean volume of the thyroid gland decreased to 13.35 $\pm 1.0 \mathrm{~mL}$ in the ultrasonographic examination $(\mathrm{P}<0.01)$.

Table 1: Volume (mean and SD) of thyroid glands in the control group, the third trimester, 6 months postpartum, and 12 months postpartum in some studies $(\mathrm{mL})$.

\begin{tabular}{|c|c|c|c|c|}
\hline & Control Group & Third Trimester & 6 Months Postpartum & 12 Months Postpartum \\
\hline Şahin et al. [3] & $12.09 \pm 2.05 \mathrm{~mL}$ & & & \\
\hline Smyth et al. [10] & $11.3 \pm 0.5 \mathrm{~mL}$ & $16.0 \pm 0.7 \mathrm{~mL}$ & & \\
\hline Sahin et al. [17] & & $14.2 \pm 7.9 \mathrm{~mL}$ & & $18.4 \pm 2.0 \mathrm{~mL}$ \\
\hline Rasmussen et al. [12] & & $24.1 \pm 2.2 \mathrm{~mL}$ & & $13.35 \pm 1.0 \mathrm{~mL}$ \\
\hline This study & $11.95 \pm 1.90 \mathrm{~mL}$ & $17.20 \pm 1.2 \mathrm{~mL}$ & $15.90 \pm 1.0 \mathrm{~mL}$ & \\
\hline
\end{tabular}

\section{Discussion}

The prevalence of thyroid diseases in the general population varies between $6.6-11.3 \%[6,7]$. This disease group includes goiter, thyroiditis, and neoplasia $[6,8]$. Breast cancer risk is also suggested to increase in thyroid diseases [9]. In a study of children in school age in Nigeria, it was found that thyroid volume did not differ significantly between boys and girls, and there was no significant difference in the size of the right and left lobes [2]. In a similar study of Japanese children, it was determined that the right thyroid lobe was significantly larger than the left but the thyroid volume was higher in girls than in boys [1]. In one study, mean thyroid volume in adult women and men was $12.09 \pm 2.05 \mathrm{~mL}$ and $14.53 \pm 2.55 \mathrm{~mL}$, respectively [3]. The mean thyroid volume was $11.3 \pm 0.5 \mathrm{~mL}$ in another study [10]. In our study, we found that the mean thyroid volume in the control group was $11.95 \pm 1.90 \mathrm{~mL}$.It is observed that thyroid volume in elderly individuals has decreased by $20.5 \%$ [4]. The mean thyroid volume was found to be greater in males than females and also in the right lobe compared to the left lobe in both genders [3]. We also found that the thyroid right lobe was larger than the left in our study, but this was not statistically significant $(\mathrm{P}>0.05)$.The volume of the thyroid is influenced by age, gender, body mass index (BMI), lean body mass, iodine intake, genetic, geographic region, and environmental factors $[3,4]$.

Loss of iodine by kidney during pregnancy and lactation is responsible for thyroid enlargement [10-13]. Thyroid size during pregnancy does not change in iodine-replete areas, but increases in iodine-deficient areas $[11,14,15]$. For this reason, more attention should be paid to iodine intake during pregnancy and lactation in iodine-deficient areas [13]. The ML dimension, CC dimension, and AP dimension of each lobe can be measured and the volume of each lobe can be calculated by the mean of the elliptical shape volume formula $[1,16]$. However, Brunn et al. applied 0.479 as an optimized conversion factor instead of $\pi / 6$ [1-6]. We also used 0.479 as conversion factor in our study.The results of the measurements made in our study are shown in Table 1 in comparison with the values found in other studies.Sahin et al. found that thyroid gland volume reached its maximum level $(14.2 \pm 7.9 \mathrm{ml})$ in the third trimester and maintained this value for another 3 months after delivery $(\mathrm{P}<0.001)$ [17]. In a study conducted by Tajtakova et al., $22 \mathrm{~mL}$ of goiter was accepted as the limit, and ultrasound was performed at 4 days after delivery, and the volume of the thyroid gland was $3.1 \mathrm{~mL}$ more than the control group $(\mathrm{P}<0.01)$.

Three months later, the examination revealed that this difference is still more meaningful $(\mathrm{P}<0.05)$ [18]. In another study, the mean thyroid gland volume $(16.0 \pm 0.7 \mathrm{~mL})$ in the third trimester was $47 \%$ higher than the control group $(\mathrm{P}<0.01)$ [10]. Rasmussen et al. found that the volume of thyroid gland increased by $30 \%$ at week 36 of gestation to $24.1( \pm 2.2) \mathrm{mL}$ and decreased to $18.4( \pm 2.0)$ $\mathrm{mL}$ after 12 months postpartum $(\mathrm{P}<0.01)$ [12]. In one study, a $13 \%$ reduction in the mean volume of the thyroid gland was detected 6 months after delivery [19].In our study, pregnant women in the third trimester had a mean thyroid volume of $17.20 \pm 1.2 \mathrm{~mL}$. This increase was statistically significant $(\mathrm{P}<0.01)$. In the sixth months postpartum, the mean gland volume in ultrasound was found to be 
$15.90 \pm 1.0 \mathrm{~mL}$. This decrease of $8 \%$ was not statistically significant $(\mathrm{P}>0.05)$. In the twelfth months after the delivery, the mean volume of the thyroid gland significant decreased to $13.35 \pm 1.0 \mathrm{~mL}(\mathrm{P}<$ 0.01).The increase in the mean volume of thyroid during pregnancy is also known as the pregnancy goiter [20]. Knowing the limits of this physiological increase will be important in distinguishing it from other possible pathologies. The thyroid gland volume is greater than $18-22 \mathrm{~mL}$ in goiter $[4,20]$. The maximum values $[17.20$ $\pm 0.9 \mathrm{~mL}$ ) we find are below these levels.

\section{Conclusion}

It is important to distinguish between physiological and pathological growth in the diagnosis and treatment of thyroid gland diseases. We think that the mean volume values we find will be useful in daily clinical practice.

\section{References}

1. Suzuki S, Midorikawa S, Fukushima T, Shimura H, Ohira T, et al. (2015) Systematic determination of thyroid volume by ultrasound examination from infancy to adolescence in Japan: The Fukushima Health Management Survey. Endocrine Journal 62(3): 261-268.

2. Marchie TT, Oyobere O, Eze KC (2012) Comparative ultrasound measurement of normal thyroid gland dimensions in school aged children in our local environment. Nigerian Journal of Clinical Practice 15(3): 285-292.

3. Şahin E, Elboğa U, Kalender E (2015) Regional Reference Values of Thyroid Gland Volumein Turkish Adults. Srp Arh Celok Lek143(3-4): 141-145.

4. Duarte GC, Araujo LMQ, Filho FM, Filho CMA, Cendoroglo MS (2017) Ultrasonographic assessment of thyroid volume in oldest-old individuals. Arch Endocrinol Metab 61(3): 269-275.

5. Brunn J, Block U, Ruf G, Bos I, Kunze WP, et al. (1981) Volumetric analysis of thyroid lobes by real-time ultrasound. Dtsch Med Wochenschr 106(41): 1338-1340.

6. Christopher C Nduka, Ademola A Adeyekun (2016) Ultrasound assessment of thyroid gland volume in diabetic patients without overt thyroid disease. Ann Afr Med 15(4): 157-162.

7. Gonio J, Szabolcs I, Kovacs Z, Kakosy T, Goth M, et al. (1994) Ultrasonography of the thyroid gland in hospitalized, chronically ill geriatric patients: thyroid volume, its relationship to age and disease, and the prevalence of diffuse and nodular goiter. J Clin Ultrasound 22(4): 257-261.

8. Pfannenstiel P, BaewChristow T (1985) Roentgen computer tomography and sonography in thyroid gland diagnosis. Zentralbl Chir 110(18): $1105-1114$

9. Özdikici M, Yıldırım H, Kılıç Y, Özder HT, Erim A, et al. (1995) Tiroid ve meme hastalıkları arasındaki ilişki. Yeni Tıp Dergisi 12(5): 377.

10. Smyth PPA, Hetherton AMT, Smith DF, Radcliff M, OHerlihy C (1997) Maternal Iodine Status and Thyroid Volume during Pregnancy: Correlation with Neonatal Iodine Intake. JCE \& M 82(9): 2840-2843.

11. Berghout A, Wiersinga W (1998) Thyroid size and thyroid function during pregnancy: an analysis. Eur J Endocrinol 138(5): 536-542.

12. Rasmussen NG, Hornnes PJ, Hegedus L (1989) Ultrasonographically determined thyroid size in pregnancy and postpartum: the goitrogenic effect of pregnancy. Am J Obstet Gynecol160(5 Pt 1):1216-1220.

13. Azizi F (2007) Iodine nutrition in pregnancy and lactation in Iran 2007, Public Health Nutrition: 10(12A): 1596-1599.

14. Berghout A, Endert E, Ross A, Hogerzeil HV, Smits NJ, et al. (1994) Thyroid function and thyroid size in normal pregnant women living in an iodine replete area. Clin Endocrinol (Oxf) 41(3): 375-379.

15. Olbricht T, Hoff HG, Benker G, Wagner R, Reinwein D (1985) Sonographic volumetry of the thyroid gland in the control of thyroxin and iodide treatment of non-toxic goiter. Dtsch Med Wochenschr 110(22): 863-866.

16. Shabana W, Peeters E, De Maeseneer M (2006) Measuring thyroid gland volume: Should we change the correction factor? American Journal of Roentgenology 186(1): 234-236.

17. Sahin SB, Ogullar S, Ural UM, Ilkkilic K, Metin Y, et al. (2014) Alterations of thyroid volume and nodular size during and after pregnancy in a severe iodine-deficient area. Clin Endocrinol (Oxf) 81(5): 762-768.

18. Tajtakova M, Hancinova D (1994 ) Pregnancy and the thyroid gland. Ceska Gynekol Apr 59(2): 54-56.

19. Nelson M, Wickus GG, Caplan RH, Beguin EA (1987) Thyroid gland size in pregnancy. An ultrasound and clinical study. J Reprod Med 32(12): 888-890.

20. Brander A, Kivisaari L (1989 ) Ultrasonography of the thyroid during pregnancy. J Clin Ultrasound 17(6): 403-406.
ISSN: 2574-1241

DOI: 10.26717/BJSTR.2018.06.001428

Mete Özdikici. Biomed J Sci \& Tech Res

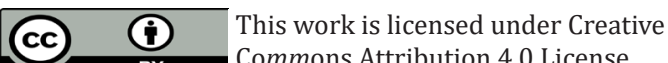

Submission Link: https://biomedres.us/submit-manuscript.php

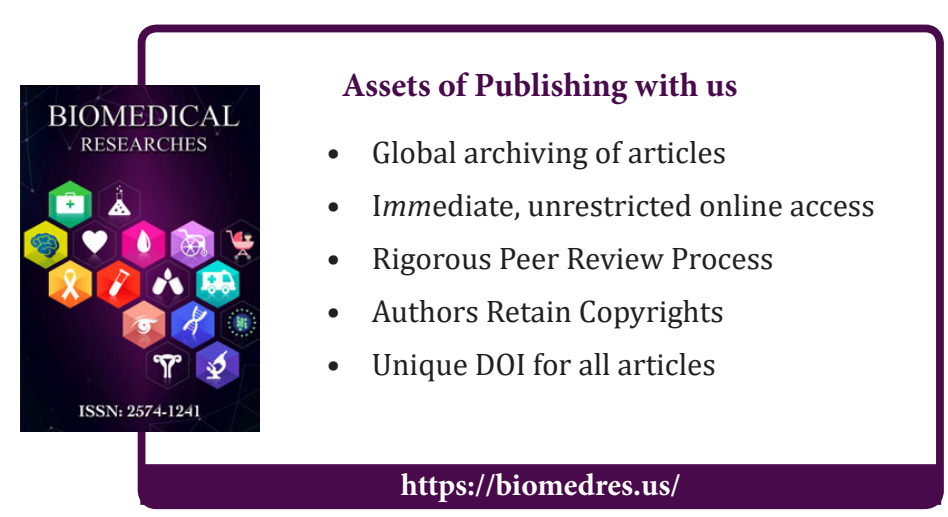

